\title{
ANALISIS PENURUNAN PONDASI TIANG BOR DENGAN METODE EMPIRIS DAN UJI BEBAN PADA PROYEK GEDUNG "K" UNIVERSITAS MUHAMMADIYAH PURWOKERTO
}

\section{ANALYSIS OF PILE CAPACITY WITH STATIC METHOD AND LOAD TEST IN "K" BUILDING PROJECTS UNIVERSITY OF MUHAMMADIYAH PURWOKERTO}

\author{
Amris Azizi ${ }^{1}$, M. Agus Salim ${ }^{2}$, Sulfah Anjarwati ${ }^{3}$ \\ ${ }^{123}$ Program Studi S1 Teknik Sipil, Fakultas Teknik dan Sains \\ Universitas Muhammadiyah Purwokerto
}

\section{Informasi Artikel \\ Dikirim, 9 Oktober 2021}

Direvisi, 30 November 2021

Diterima, 27 Desember 2021

\section{Korespondensi Penulis:}

Amris Azizi

Program Studi Teknik Sipil Universitas Muhammadiyah Purwokerto

JL. K.H. Ahmad Dahlan

Purwokerto, 53182

amrissampang11@gmail.com

\section{ABSTRAK}

Gedung "K" Universitas Muhammadiyah Purwokerto dirancang menggunakan pondasi tiang bor dengan kedalaman ujung mencapai 16 meter. Dalam pelaksanaan pekerjaan pondasi, sering dijumpai kondisi tanah pada kedalaman yang sama mempunyai karakteristik yang berbeda. Hal ini dapat mempengaruhi ketercapaian kedalaman pondasi yang direncanakan, mempengaruhi kualitas, kapasitas dukung dan besarnya penurunan pondasi. Penelitian ini menganalisis besarnya penurunan pondasi tiang menggunakan metode statik (pendekatan teoritis) kemudian dibandingkan dengan penurunan pondasi tiang hasil uji beban metode Pile Driving Analyzer (PDA). Analisis diperlukan untuk memastikan penurunan pondasi terpasang masih dalam batas-batas yang diijinkan.

Hasil analisis menunjukkan penurunan pondasi tiang dengan cara statik pada tiang BP4 dan BP6 adalah 0,25 dan 0,24 mm, jauh lebih kecil dibandingkan dengan penurunan pondasi tiang hasil uji pembebanan dilapangan, yaitu sebesar $3 \mathrm{~mm}$. Penurunan pondasi tiang tunggal dengan cara statik maupun hasil uji lapangan masih dibawah batas maksimum penurunan yang diijinkan.

Kata Kunci : penurunan, pondasi tiang

The " $K$ " building of the University of Muhammadiyah Purwokerto was designed using a drill pile foundation with a tip depth of 16 meters. In implementatiom foundation work, it is often found that soil conditions at the same depth have different characteristics. This can affect the achievement of the planned foundation depth, affect the quality, bearing capacity and magnitude of foundation settlement.

This study analyzes the magnitude of the pile foundation settlement using the static method (theoretical approach) and then compared it with the pile foundation settlement as a result of the Pile Driving Analyzer (PDA) load test method. Analysis is needed to ensure that the settlement of the installed foundation is still within the allowable limits. The results of the analysis showed that the static settlement of the pile foundation on the BP4 and BP6 piles was 0.25 and $0.24 \mathrm{~mm}$, much smaller than the decrease in the pile foundation as a result of field loading tests, which was $3 \mathrm{~mm}$. The settlement of single pile foundation by static method and the results of field tests are still below the maximum allowable settlement.

Keyword : settlement, pile foundation 


\section{PENDAHULUAN}

Struktur bangunan dibedakan menjadi struktur bawah dan struktur atas. Struktur atas adalah struktur bangunan yang terletak diatas permukaan tanah, sedangkan struktur bawah adalah struktur bangunan yang terletak di bawah permukaan tanah. Struktur bawah umumnya disebut pondasi. Pondasi berfungsi memikul beban bangunan dan beban lainnya yang turut diperhitungkan dan meneruskannya ke dalam tanah sampai ke lapisan atau kedalaman tertentu.

Tanah yang tidak mampu memikul beban yang diteruskan pondasi akan mengalami penurunan berlebihan atau keruntuhan. Hal tersebut akan menyebabkan kerusakan konstruksi yang berada diatasnya. Kegagalan pondasi karena penurunan dapat berlangsung relatif cepat, atau melalui proses yang lambat dan berlangsung sampai bertahun-tahun.

Besar dan lamanya penurunan sangat ditentukan oleh besarnya tekanan yang bekerja dan jenis tanah di dasar pondasi. Penurunan pada tanah berbutir kasar dan berbutir halus, khususnya lempung, mempunyai karakteristik yang berbeda. Pada tanah lempung ekspansif yang mempunyai sifat kembang-susut besar, dimusim penghujan tanah dasar akan berada pada kondisi kuat geser terburuk, karena kadar air yang sangat tinggi. Dimusim kemarau tanah ekspansif cenderung menyusut karena banyaknya volume air yang dilepas, kondisi ini dapat menyebabkan retak-retak pada tanah. Pada kedua kondisi ini tanah lempung berpotensi mengalami kegagalan dalam mendukung pondasi.

Bila dasar pondasi terletak pada tanah granuler seperti pasir dan kerikil, penurunan yang terjadi adalah berupa penurunan segera. Penurunan total, berlangsung dan selesai pada waktu segera setelah beban diterapkan. Penurunan pondasi yang terletak pada tanah-tanah lanau dan pasir, sebagian disebabkan oleh deformasi tanah dasar pondasi kearah lateral. Jika kerikil dalam kondisi tidak padat, penurunan mendadak terjadi bila terdapat getaran frekwensi tinggi. Berbagai macam pondasi dapat digunakan pada kerikil padat tanpa penurunan yang berarti (Hardiyatmo, 2002).

Analisis penurunan memainkan peran penting dalam pondasi bangunan, meskipun hanya sedikit bangunan modern yang runtuh disebabkan penurunan yang berlebihan. Umumnya yang terjadi adalah keruntuhan parsial atau kegagalan lokal pada bagian struktur. Penurunan yang berlebihan dan pergerakan diferensial dapat menyebabkan distorsi dan retakan pada struktur. (Gabrielaitis, et.al.,2013)

Analisis dan perhitungan penurunan pondasi dapat dilakukan dengan metode empiris dan uji pembebanan di lapangan (metode dinamik). Metode empiris atau metode statik menggunakan prinsip-prinsip mekanika tanah, sedangkan uji lapangan dengan metode dinamik atau sering disebut Pile Driving Analyzer (PDA).

Gedung "K" Universitas Muhammadiyah Purwokerto dirancang dengan ketinggian sepuluh lantai menggunakan pondasi tiang bor. Ujung bawah pondasi mencapai kedalaman rata-rata 16 meter. Dalam pelaksanaan pekerjaan, sering dijumpai kondisi tanah pada kedalaman yang sama mempunyai karakteristik yang berbeda. Hal ini tentu saja dapat mempengaruhi ketercapaian kedalaman pondasi yang direncanakan, dan dapat mempengaruhi kualitas, kapasitas dukung dan besarnya penurunan pondasi.

Penelitian ini menghitung dan menganalisis penurunan pondasi tiang Gedung " $\mathrm{K}$ " Universitas Muhammadiyah Purwokerto menggunakan metode statik (pendekatan teoritis empiris) kemudian dibandingkan dengan penurunan pondasi tiang hasil uji beban metode PDA.

\section{METODE PENELITIAN}

Dalam penelitian ini, besarnya penurunan pondasi tiang tunggal dan kelompok dihitung dengan persamaan yang disarankan Poulus dan Davis (1980) (Persamaan 1 sampai 4)

Untuk tiang tunggal, penurunan dihitung dengan rumus sebagai berikut.

$$
\begin{aligned}
& S=\frac{P u I}{E s d} \\
& I=I_{o} R_{k} R_{b} R_{\mu}
\end{aligned}
$$

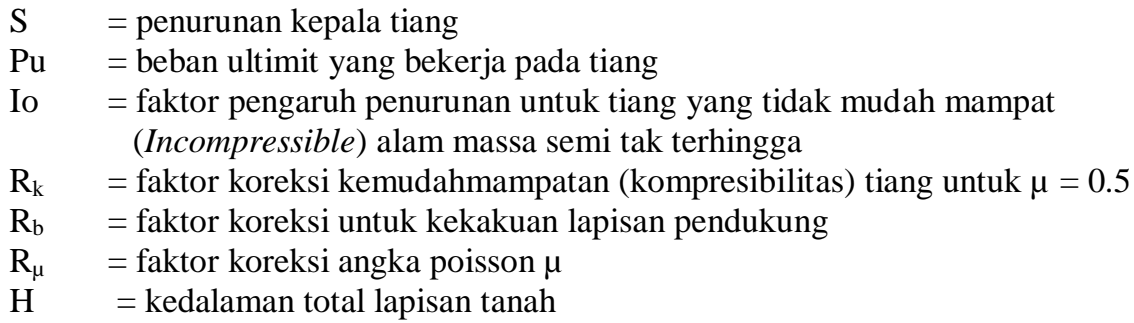


Ukuran kompresibilitas relatif antara tiang dan tanah yang dinyatakan oleh persamaan:

$$
K=\frac{E p}{E s}
$$

$\mathrm{K} \quad$ = faktor kekakuan tiang

$\mathrm{E}_{\mathrm{p}} \quad=$ modulus elastisitas bahan tiang

$\mathrm{E}_{\mathrm{s}} \quad=$ modulus elastisitas tanah

Untuk penurunan kelompok tiang, Skempton, Yassin dan Gibson (1953) dalam Hardiyatmo (2002) menyarankan hubungan empiris penurunan kelompok tiang dengan lebar kelompok tiang, terhadap penurunan tiang tunggal.

Hubungan penurunan antara tiang tunggal dan kelompok tiang sebagai berikut:

$$
\frac{S g}{S}=\frac{(4 B+3)^{2}}{(B+4)^{2}}
$$

$\mathrm{Sg} \quad=$ penurunan kelompok tiang $(\mathrm{m})$

$\mathrm{B} \quad=$ lebar kelompok tiang $(\mathrm{m})$

$\mathrm{S} \quad=$ penurunan tiang tunggal pada intensitas beban yang sama $(\mathrm{m})$

Dari data hasil uji PDA didapatkan penurunan pondasi tiang termobilisasi. Hasil uji PDA akan dibandingkan dengan hasil analisis metode statis (empiris). Dalam analisis metode statis, penurunan tiang tunggal dihitung dengan rumus yang disarankan oleh Poulus dan Davis, sedangkan penurunan kelompok tiang dengan rumus Skempton, Yassin dan Gibson.

Dalam analisis perbandingan penurunan pondasi tiang ini, kondisi dan parameter tanah di lapangan dianggap sama untuk uji PDA dan uji N-SPT. Beban yang diterapkan dan profil pondasi yang diuji sama untuk uji PDA dan uji N-SPT.

\section{HASIL DAN PEMBAHASAN}

\subsection{Kondisi Lapisan Tanah} dan 2.

Hasil uji bor dalam dan SPT pada 2 titik, memberikan ilustrasi nilai N-SPT dan lapisan tanah pada Tabel 1

Tabel 1. Perkiraan Lapisan Tanah Berdasarkan Standard Penetration Test (SPT) pada Titik Bor DB-1

\begin{tabular}{ccccc}
\hline Titik Bor & Depth $(\boldsymbol{m})$ & N-SPT & Jenis Tanah & Keterangan \\
\hline & $0.00-3.00$ & 3 & Soft silty clay & GWL berada pada kedalaman -5.15 \\
\cline { 2 - 4 } & $3.00-6.00$ & 14 & Medium dense silty sand & \\
\cline { 2 - 4 } & $6.00-8.00$ & 15 & Medium dense sand trace gravel & \\
\cline { 2 - 4 } DB-1 & $8.00-10.00$ & 45 & Dense sandy gravel & \\
\cline { 2 - 4 } & $10.00-12.00$ & 60 & Very dense sandy gravel & \\
\cline { 2 - 5 } & $12.00-14.00$ & 5 & Loose silty sandy gravel & Lery dense sandy silt trace gravel \\
\cline { 2 - 4 } & $14.00-16.00$ & 60 & Very dense sandy gravel & $\begin{array}{c}\text { tanah pendukung (bearing layer) } \\
\text { dengan ketebalan lapisan } \pm 16 \mathrm{~m}\end{array}$ \\
\cline { 2 - 5 } & $16.00-30.03$ & 60 & &
\end{tabular}

Tabel 2. Perkiraan Lapisan Tanah Berdasarkan Standard Penetration Test (SPT) pada Titik Bor DB-2

\begin{tabular}{ccccc}
\hline Titik Bor & Depth $(\boldsymbol{m})$ & N-SPT & Jenis Tanah & Keterangan \\
\hline & $0.00-4.00$ & $4-5$ & Medium silty clay trace sand & GWL berada pada kedalaman -5.00 \\
\cline { 2 - 5 } & $4.00-6.00$ & 29 & Medium dense sand trace gravel & \\
\cline { 2 - 5 } & $6.00-8.00$ & 23 & Medium dense silty sand & \\
\cline { 2 - 5 } & $8.00-10.00$ & 41 & Dense sandy gravel & $\begin{array}{c}\text { Lapisan tanah keras sebagai laisan } \\
\text { tanah pendukung (bearing layer) } \\
\text { dengan ketebalan lapisan } \pm 10 \text { m }\end{array}$ \\
\hline Sumber: Cipta, PT (2017) & 60 & Very dense sandy gravel &
\end{tabular}




\subsection{Pilihan pondasi}

Untuk struktur sedang sampai dengan berat, dari uji SPT diatas, pilihan pondasi adalah pondasi tiang bor. Ujung tiang bertumpu pada lapisan tanah keras sebagai lapisan tanah dasar pendukung (bearing layer) seperti ditunjukkan oleh N-SPT > 50 yang cukup stabil pada rentang kedalaman -14.00 - 15.00 meter di bawah muka tanah eksisting. Perkiraan kapasitas dukung ijin aksial (tekan) dan tarik pondasi tiang ditunjukkan pada Tabel 3 dan 4.

Tabel 3. Rekomendasi Perkiraan Kapasitas Dukung Ijin Axial Load (tekan) Pondasi Tiang Bor Berdasarkan Hasil Uji N-SPT

\begin{tabular}{|c|c|c|c|c|c|}
\hline \multirow{2}{*}{$\begin{array}{l}\text { Titik } \\
\text { Bor }\end{array}$} & \multirow{2}{*}{$\begin{array}{l}\text { Depth } \\
\text { (m) }\end{array}$} & \multicolumn{3}{|c|}{$\begin{array}{l}\text { Qall axial load } \\
\text { (ton) }\end{array}$} & \multirow[t]{2}{*}{ Remarks } \\
\hline & & $\phi 60 \mathrm{~cm}$ & $\phi 80 \mathrm{~cm}$ & $\phi 100 \mathrm{~cm}$ & \\
\hline DB-1 & 15.00 & 63 & 107 & 162 & \\
\hline DB-2 & 14.00 & 69 & 115 & 173 & \\
\hline
\end{tabular}

\section{Penurunan Pondasi Hasil Uji PDA dan Analisis CAPWAP}

Penurunan pondasi tiang berdasarkan uji PDA dan analisis CAPWAP terlihat dalam Tabel 4 Penentuan tiang uji dilakukan pada satu tiang yang dipilih secara random.

Tabel 4. Penurunan Tiang Hasil Uji PDA dan Analisis CAPWAP

\begin{tabular}{ccc}
\hline \multirow{2}{*}{ ID tiang } & \multicolumn{2}{c}{ Penurunan Tiang (mm) } \\
\cline { 2 - 3 } & Maksimum & Permanen \\
\hline$\# 50$ & 3 & 1 \\
\hline Sumber: Ageotescon, 2019 & &
\end{tabular}

Perhitungan Penurunan Pondasi Metode Statik

\section{Penurunan tiang tunggal}

$$
\begin{aligned}
& S=\frac{P u I}{E s d} \\
& I=I_{o} R_{k} R_{b} R_{\mu}
\end{aligned}
$$

Mutu beton tiang bor K-300, fc' $=300 \times 0,83 / 0,098=24,4 \mathrm{Mpa}$

Tiang berada pada tanah pasir, maka modulus elastisitas bahan tiang:

$$
\begin{aligned}
\mathrm{Ep} & =4.700 \sqrt{\mathrm{fc}}{ }^{\prime} \\
& =4.700 \sqrt{2} 24,4 \\
& =23.217 \mathrm{MPa}
\end{aligned}
$$

$\mathrm{K}=\mathrm{Ep} / \mathrm{Es}=23.217 / 5,25=4.422$

$\mathrm{L} / \mathrm{d}=16 / 0,6=26,67$

$\mathrm{d}_{\mathrm{b}} / \mathrm{d}=0,6 / 0,6=1$

Rasio poisson bahan tiang $\mu=0,3$

Dari Gambar 1, $\mathrm{I}_{\mathrm{o}}=0,073$

Dari Gambar 2, $\mathrm{R}_{\mathrm{k}}=1,3$

Dari Gambar 3, untuk $\mathrm{E}_{\mathrm{b}} / \mathrm{E}_{\mathrm{s}}=1, \mathrm{Rb}=1$

Dari Gambar 4, $\mathrm{R}_{\mu}=0,92$

Besarnya penurunan pondasi pada Tabel 5. 


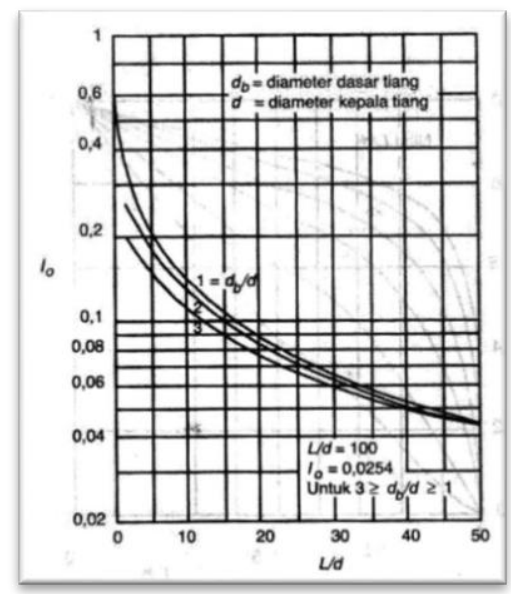

Gambar 1. Faktor penurunan Io

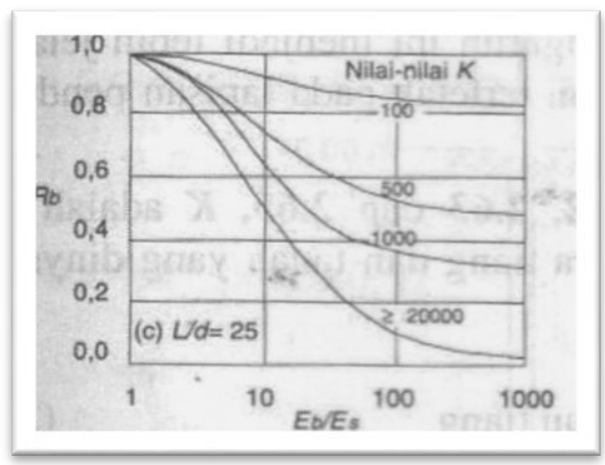

Gambar 3. Koreksi Kekakuan

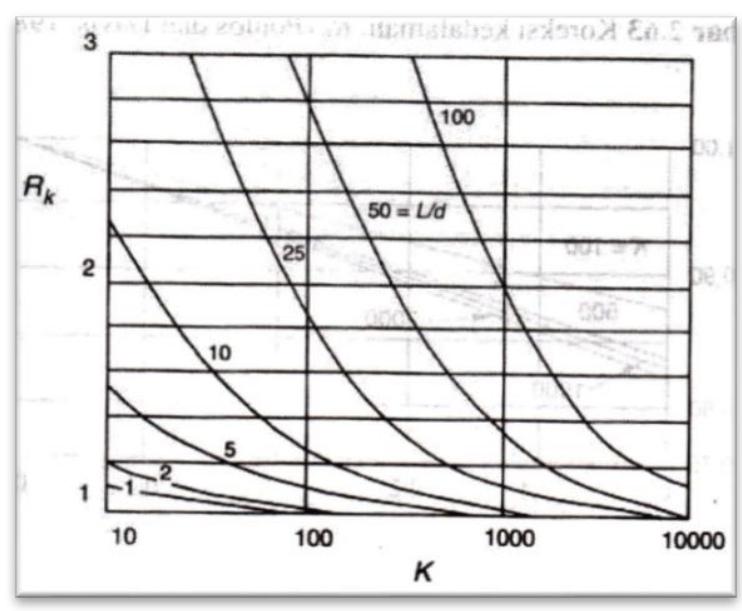

Gambar 2. Koreksi Kompresi, Rk

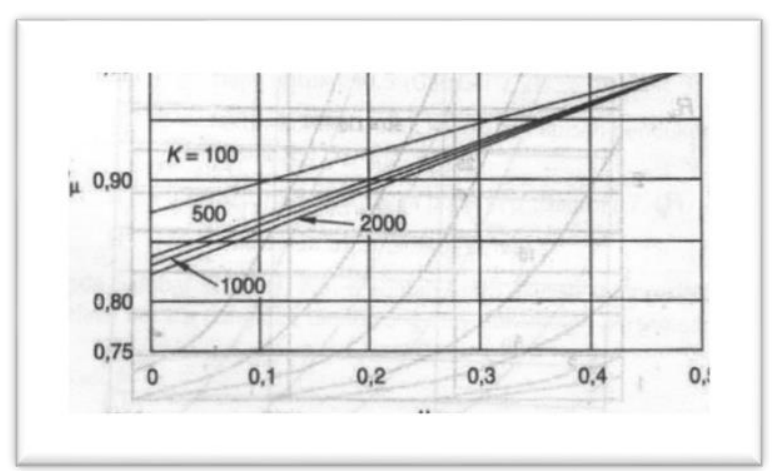

Gambar 4. Koreksi Angka Poisson, $\mathrm{R}_{\mu}$

Tabel 5. Penurunan Pondasi Tunggal Metode Statis

\begin{tabular}{cccccccccc}
\hline $\begin{array}{c}\text { Sampel } \\
\text { Tiang }\end{array}$ & $\begin{array}{c}\text { Pu } \\
(\mathbf{k N})\end{array}$ & $\mathbf{I}_{\mathbf{0}}$ & $\mathbf{R}_{\mathbf{k}}$ & $\mathbf{R}_{\mathbf{b}}$ & $\mathbf{R}_{\boldsymbol{\mu}}$ & $\begin{array}{c}\boldsymbol{I} \\
\left(\boldsymbol{I}_{\boldsymbol{o}} \boldsymbol{R}_{\boldsymbol{k}} \boldsymbol{R}_{\boldsymbol{b}} \boldsymbol{R}_{\boldsymbol{\mu}}\right)\end{array}$ & Es & d & $\begin{array}{c}\boldsymbol{S}=\frac{\boldsymbol{P u} \boldsymbol{E}}{\boldsymbol{E s} \boldsymbol{d}} \\
(\mathbf{m m})\end{array}$ \\
\hline BP4 & 902,86 & 0,073 & 1,3 & 1 & 0,92 & 0,0087 & 5.250 & 0,6 & 0,25 \\
BP6 & 866,32 & 0,073 & 1,3 & 1 & 0,92 & 0,0087 & 5.250 & 0,6 & 0,24 \\
\hline
\end{tabular}

\section{Penurunan tiang kelompok}

$$
\begin{array}{ll}
\frac{S g}{S}=\frac{(4 B+3)^{2}}{(B+4)^{2}} \\
\text { Sg } \quad=\text { penurunan kelompok tiang }(\mathrm{m}) \\
\mathrm{B} \quad=\text { lebar kelompok tiang }(\mathrm{m}) \\
\mathrm{S} \quad=\text { penurunan tiang tunggal pada intensitas beban yang sama }(\mathrm{m})
\end{array}
$$




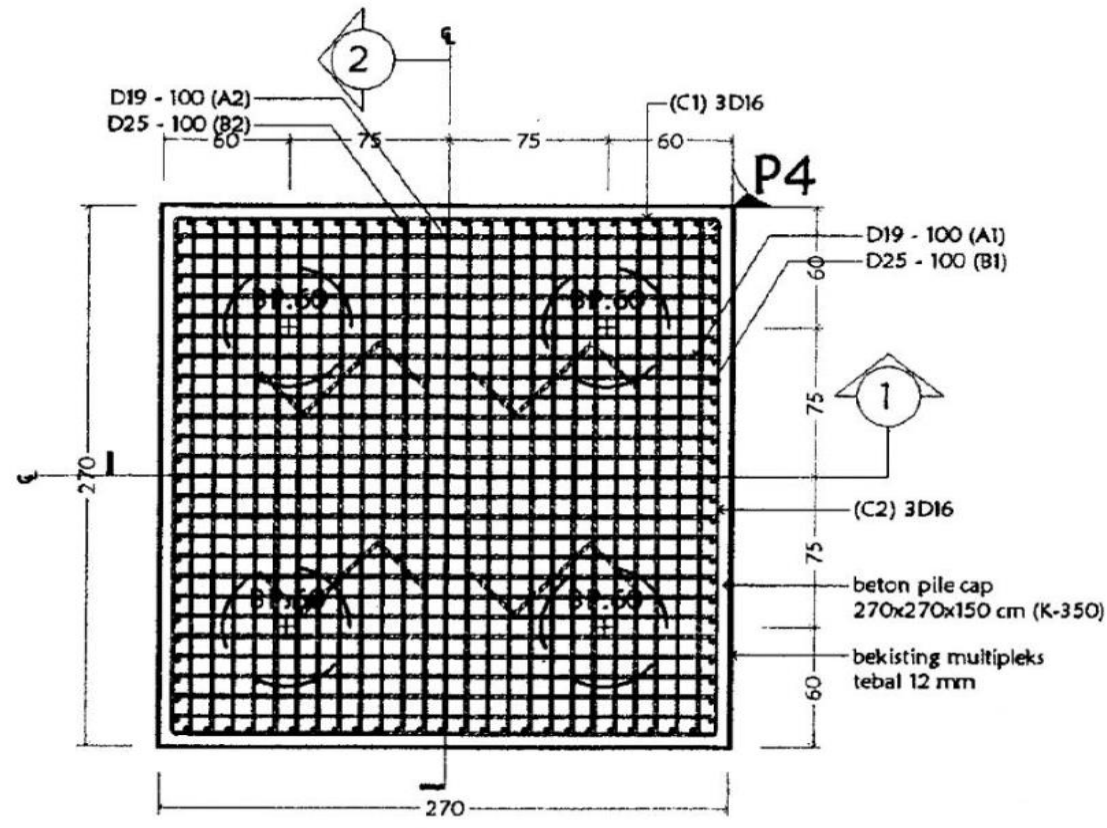

Gambar 5. Ukuran Pile Cap Pondasi BP4

Tabel 6. Penurunan Pondasi Kelompok Metode Statis

\begin{tabular}{cccc}
\hline Sampel Tiang & B & S & Sg \\
& $(\mathbf{m})$ & $(\mathbf{m})$ & 0,0087 \\
\hline BP4 & 2,1 & 0,0025 & 0,0125 \\
BP6 & 3,6 & 0,0024 &
\end{tabular}

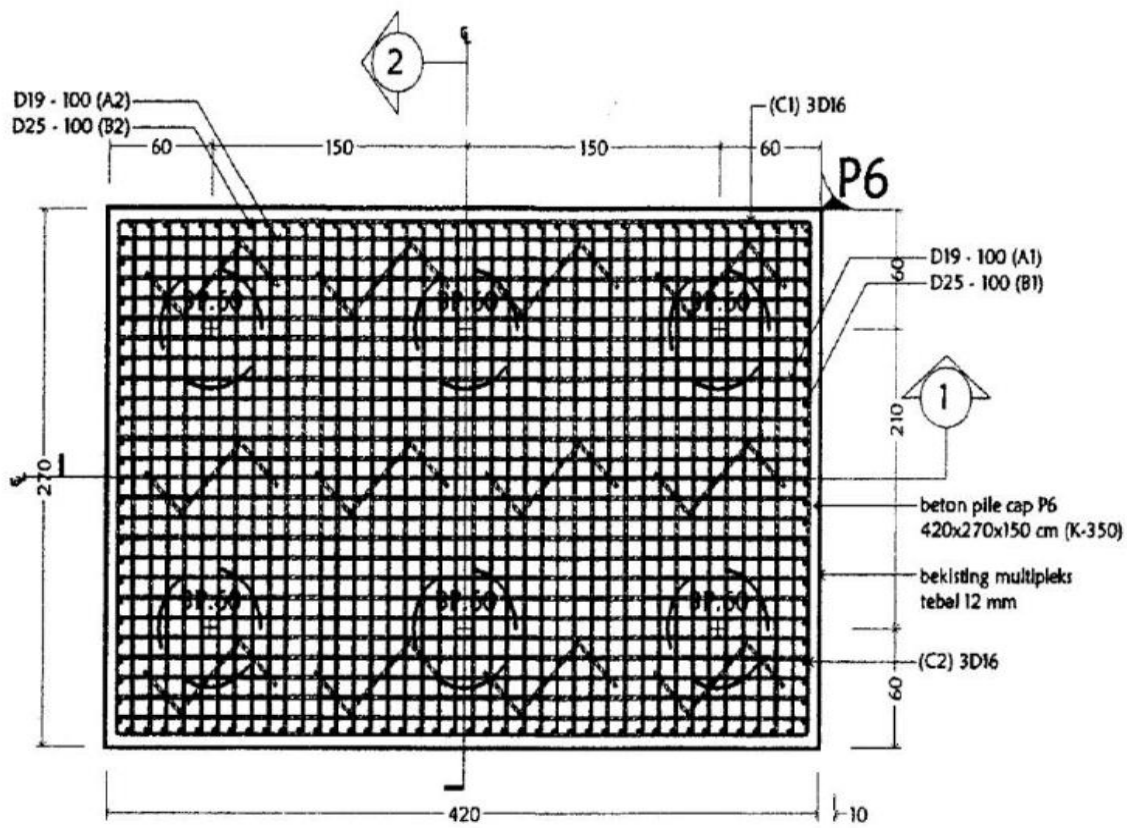

Gambar 6. Ukuran Pile Cap Pondasi BP6

Besarnya penurunan pondasi hasil perencanaan, uji PDA, CAPWAP dan analisis metode statik dapat dilihat dalam Tabel 7.

CIVeng Vol.3, No.1, Januari $2022: 25 \sim 32$ 
Tabel 7. Penurunan Pondasi Tiang Tunggal hasil Perencanaan, PDA, CAPWAP dan Analisis Metode Statik.

\begin{tabular}{ccc}
\hline \multirow{2}{*}{$\begin{array}{c}\text { ID } \\
\text { tiang }\end{array}$} & CAPWAP dan Analisis Metode Statik. \\
\hline \multirow{2}{*}{ M50 } & Perencanaan & $\begin{array}{c}\text { Penurunan Pondasi Maksimum } \\
(\mathbf{m m})\end{array}$ \\
\cline { 2 - 3 } & PDA dan CAPWAP & - \\
\hline BP4 & Analisis Statik & 3 \\
\hline BP6 & & 0,25 \\
\hline Sumber: data sekunder dan hasil analisis, 2021 & 0,24 \\
\hline
\end{tabular}

Dalam Tabel 7 diatas terlihat penurunan tiang tunggal hasil analisis statik lebih kecil dibanding hasil uji PDA, CAPWAP. Data penurunan tiang hasil perencanaan tidak ada. Hasil dalam tabel diatas menggambarkan bahwa penurunan pondasi terpasang lebih besar dari penurunan hasil analisis. Hal ini disebabkan karena pada saat uji penurunan dilapangan beban pada pondasi sudah termobilisasi.

Besarnya penurunan tiang tunggal ini lebih kecil atau masih dibawah batas toleransi penurunan yang disyaratkan SNI 8460:2017 (<15+b/600 cm). Dengan demikian dapat dikatakan bahwa pondasi terpasang cukup aman terhadap penurunan yang terjadi. Sedangkan penurunan pondasi kelompok tiang seperti pada Tabel 5.7 menunjukkan bahwa penurunannya sangat kecil, jauh dari batas maksimum penurunan yang diijinkan.

\section{KESIMPULAN}

Berdasarkan hasil analisis dan pembahasan yang telah dilakukan, dapat ditarik kesimpulan sebagai temuan penelitian sebagai berikut:

1. Penurunan pondasi tiang dengan cara statik pada tiang BP4 dan BP6 adalah 0,25 dan 0,24 mm, jauh lebih kecil dibandingkan dengan penurunan pondasi tiang hasil uji pembebanan dilapangan, yaitu sebesar $3 \mathrm{~mm}$.

2. Penurunan pondasi tiang tunggal dengan cara static maupun hasil uji lapangan masih dibawah batas maksimum penurunan yang diijinkan

\section{DAFTAR PUSTAKA}

[1] Badan Standardisasi Nasional. 2017. SNI 8460:2017 (Persyaratan Perancangan Geoteknik), Jakarta

[2] Fahriani, F., dan Yayuk Apriyanti. 2015. Analisis Daya Dukung Tanah dan Penurunan Pondasi Pada Daerah Pesisir Pantai Utara Kabupaten Bangka, Jurnal Fropil, Vol 3 Nomor 2 Juli-Desember 2015.

[3] Gabrielaitis,L., Vytautas Papinigis, dan Gintaras Žaržojus. 2013. Estimation of Settlements of Bored Piles Foundation, 11th International Conference on Modern Building Materials, Structures and Techniques,MBMST, Procedia Engineering 57 ( 2013 ) 287 - 293, www.sciencedirect.com

[4] Hardiyatmo, H., C. 2002. Teknik Fondasi II, Edisi ke 1, Jurusan Teknik Sipil, Fakutas Teknik, Universitas Gadjah Mada, Yogyakarta.

[5] Luthfiani, F., Ilham Nurhuda, dan Indrastono D.A. 2017. Analisis Penurunan Bangunan Pondasi Tiang Pancang dan Rakit Pada Proyek Pembangunan Apartemen Surabaya Central Bussiness District, Jurnal Karya Teknik Sipil, Volume 6, Nomor 2, Tahun 2017.

[6] Noor, A., dan Shella Octaviani. 2014. Evaluasi Perkiraan Daya Dukung Teoritis Terhadap Daya Dukung Aktual Tiang Berdasarkan Data Sondir dan Loading Test, Jurnal INTEKNA, Tahun XIV, No.1, Mei 2014.

[7] Nugraha, A.S., dan Angel Refanie. 2015. Analisis Beban-Penurunan Pada Pondasi Tiang Bor Berdasarkan Hasil Uji Beban Tiang Terinstrumentasi dan Program GEO5, Jurnal Teknik Sipil, Volume 11 Nomor 2, Oktober 2015.

[8] Putri, M.S., Yayuk Apriyanti, dan Ferra Fahriani. 2018. Analisis Perbandingan Daya Dukung dan Penurunan Tiang Pancang Tunggal Dengan Metode Statik dan Uji Beban, Prosiding Seminar Nasional Penelitian dan Pengabdian Pada Masyarakat, Universitas Bangka Belitung. Pangkalpinang.

[9] Smith, P. S., N.Hytiris, dan S. Mickovski. 2015. Comparison of Settlement Calculation Methods for The Design of a Gravity Base Foundation in Deep Water, Proceedings of the XVI ECSMGE Geotechnical Engineering for Infrastructure and Development. 
